\title{
US consumer purchasing decisions and demand for apparel
}

US consumer purchasing decisions

\author{
Mohamadou L. Fadiga and Sukant K. Misra
}

Department of Agricultural and Applied Economics, Texas Tech University, Lubbock, Texas, USA, and

Octavio A. Ramirez

Department of Agricultural Economics and Agricultural Business, New Mexico State University, Las Cruces, New Mexico, USA

\begin{abstract}
Purpose - The purpose of this is study is to identify sources of demand growth for apparel in the US based on consumer demographic profiles, regions, and product characteristics.

Design/methodology/approach - A two-step procedure was utilized to model, estimate, and analyze purchasing decision and consumer demand for nine apparel products (male shirts, shorts, jeans and slacks and female slacks, skirts, shorts, dresses and jeans). This study is based on a survey conducted by the American shoppers' panel, which collects consumption data of various garments, socioeconomic profiles, and product characteristics.

Findings - The results indicate that purchase decisions are determined by garments' own prices, age, female employment, gender, regions, and the presence of children. The stucly also shows evidence that the effect of product-specific pricing strategies would be limited to the targeted products and the origin of the product has minimal effect on consumer expenditures on apparel.

Originality/value - This study is one of the few that have used disaggregated apparel products and detailed demographic factors, thus has clear marketing implications and can be useful to the apparel industry.
\end{abstract}

Keywords Clothing, Buying behaviour, United Siates of Anerica

Paper type Research paper

\section{Introduction}

The apparel industry is an important segment of the US economy, with total annual domestic sales and exports in 2003 evaluated at 183 and 5.2 billion dollars, respectively (USDC, 2004). However, US imports of apparel have increased during the last decade, with a noticeable import surge from 41 billion dollars in 1995 to 61.2 billion dollars in 2003 (USDC, 2004). This import surge has resulted in a clecrease in the US textile mill use of domestically produced cotton fibres from 11.34 million bales in 1997 to 7.69 million bales in 2002 (USDA, 2004).

As the world's major apparel exporters continue to claim increasing shares of the US market, the US apparel manufacturers are facing the need to design new strategies to improve the competitiveness of the industry. To meet domestic consumer demand profitably under volatile market conditions, the US apparel industry must clearly understand the determining factors that shape domestic consumption of various apparel products. In that regard, information about prices, quality attributes, country of origins, and consumer profiles, is critical for designing effective marketing strategies. This study, therefore, seeks:

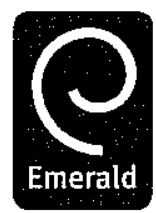

Journal of Fasthion Narketing and Nanagernerst Vol. 9 No. 4, 2005 pp. 367.379 (2) Emerald Group Publishing Limited DOI 10.1109/13612020510520759 
$\underset{9,4}{\mathrm{JFMM}}$

368
(1) to analyze and model the demand for apparel in the US;

(2) to quantify the relationship between expenditure shares of nine apparel products (male shirts, female jeans, male jeans, female shorts, male shorts, female slacks, male slacks, skirts, and dresses) and four different cotton blends (100 percent, between 75 and 99 percent, between 50 and 74 percent, and less than 50 percent), and

(3) to identify sources of demand growth based on consumer profiles and regions.

It is hypothesized that the results would provide a better understanding of consumer demand for apparel in the US.

Consumer demand for apparel and related products has been widely studied in the fields of home economics and consumer science. Norum (1989) and Mokhtari (1992) addressed the dynamic aspect of consumer demand for apparel while focusing on the effects of education level, gender, age, and marital status. Norum (1999) used demographic variables to measure changing tastes in demand for accessories, footwear, and hosiery. Wagner (1986), DeWeese and Norton (1991) and Abel-Ghany and Schwenk (1993) analyzed the effects of family characteristics on expenditures for apparel and textile home furnishings focusing exclusively on the influence of gender and race. Lee et al. (1997) studied apparel expenditure patterns among elderly consumers, hypothesizing a non-linear relationship between age and expenditures. Schwer and Daneshvary (1995) addressed the issue of symbolic product attributes and the phenomenon of emulatory behaviour in apparel consumption using the rodeo society as a reference group and western clothing as symbolic products.

These studies, in general, quantified the marginal impacts of demographic variables and the responsiveness of consumer demand for apparel to price and total expenditures and concluded that apparel is price and income-elastic in the short run and less so in the long run. However, the fact that most of these studies analyzed clothing as a single product, because of data limitations, hinders their usefulness to the apparel industry.

\section{Conceptual analysis and model derivation}

Following Perali and Chavas (2000), the analysis of consumer demand for apparel in this study is conceptualized using a random utility framework. An indirect utility function specified as a function of deterministic components (i.e. vector of purchased apparel and vector of socioeconomic and demographic factors, product characteristics, and seasons) and stochastic component. As Brown and Walker (1989) stated, the random utility framework is important for two reasons. First, it determines the structure of the error terms in the derived demand equations and second, it provides a consistent framework that reconciles the fundamental assumption of demand theory (i.c. consumers are rational utility maximisers) and the inherent random nature of applied demand modelling (i.e. measurement errors and errors due to information asymmetry). Under a random utility framework, the error terms are not observable and may vary with respect to the prevailing unit of analysis (i.e. individual or household), goods, or time, and are assumed to follow a normal distribution.

The composite nature of apparel and the multidimensional aspect of the characteristics they embody require some degree of flexibility in the utility function that maps consumer choices for apparel. The proposed indirect utility function is 


$$
\ln V_{t}\left(m_{t}, p_{t}, d_{t}\right)=\frac{\ln \left[m_{t} / \pi\left(p_{t}, d_{t}\right)\right]}{\ln \psi\left(p_{t}, d_{t}\right)}+\varepsilon_{t}
$$

US consumer purchasing decisions

where in represents natural logs of the variable in question, $\pi\left(p_{t}, d_{t}\right)$ and $\psi\left(p_{l}, d_{t}\right)$ are non-linear price index equations defined as

$$
\begin{aligned}
& \ln \pi\left(p_{t}, d_{t}\right)=\alpha_{0}+\sum_{k=1}^{n} \alpha_{k}\left(d_{l}\right) \ln \left(p_{k t}\right)+\frac{1}{2} \sum_{k=1}^{n} \sum_{j=1}^{n} \gamma_{k j} \ln \left(p_{k t}\right) \ln \left(p_{j t}\right) \\
& \ln \psi\left(p_{t}, d_{t}\right)=\sum \beta_{j}\left(d_{t}\right) \ln \left(p_{j t}\right) .
\end{aligned}
$$

In this specification,

$$
m_{t}=\sum p_{i t} q_{i t}
$$

is the total expenditures by a household at time $t ; d_{t}$ represents the demographic factors, apparel characteristics, or seasonal dummies; $p_{t}$ the price of apparel; and $\varepsilon_{l}$ is a stochastic error term. Applying Roy's identity to equation (1) yields a share equation specified as

$$
\bar{w}_{i t}=\partial \ln \left[\pi\left(p_{t}, d_{t}\right)\right] / \partial \ln \left(p_{i t}\right)+\left[\partial \ln \left(\psi\left(p_{t}, d_{t}\right)\right) / \ln \left(p_{i t}\right)\right] \times \ln \left[m_{t} / \pi\left(p_{t}, d_{t}\right)\right] .
$$

This relationship is the foundation of the expenditure model for apparel which, ignoring subscript for household, can be mathematically expressed as

$$
\bar{w}_{i t}=\alpha_{i}+\sum z_{i} d_{t}+\sum \gamma_{i j} \ln \left(p_{j t}\right)+\beta_{i}\left(d_{t}\right) \ln \left[m_{t} / \pi\left(p_{t}, d_{t}\right)\right]+\varepsilon_{i t},
$$

where $\bar{w}_{i l}$ represents the latent expenditure share for the $i$ th apparel by a household at time $t ; p_{j l}$ is the price of the $j$ th garment at period $t$. The coefficient $\beta_{i}\left(d_{l}\right)$ is a function of the socioeconomic and demographic factors that impact apparel expenditures, which following Blundell et al. (1993), is defined as

$$
\beta_{i}\left(d_{t}\right)=\beta_{i}+\beta_{i} D_{t},
$$

where $D_{t}$ is a dummy variable indicating household characteristics (i.e. race, the presence of children, gender, income strata, and female employment status), product characteristics (cotton blends and product origins). Specifying the parameters of the total expenditures in this manner accommodates for inferior, complementary, and substitute goods, and provides a consistent framework to account for the effects of socioeconomic, demographic, seasonal variables, and product characteristics on expenditure shares.

Modelling consumer demand for apparel is influenced by the frequency of purchase of apparel. It is quite typical for households to make a conscientious decision not to purchase any garments because of unfavourable prevailing prices, seasons, stocks level, or budget constraints faced at the time of their decision. Pudney (1989) elaborated on this strategic household decision-making process and interpreted the absence of purchases as true comer solutions resulting from utility maximization behaviour. This is important in the sense that past expenditure on apparel is assumed to have an impact on the decision to purchase rather than how much to purchase. For this reason, 
JFMM

9,4 the derived expenditure share model does not incorporate a stock adjustment indicator although apparel may be considered as a semi-durable good.

\section{Model specification and estimation}

The frequency of zero expenditure requires a modelling approach that accounts for the purchase decision-making process. The probit model is used to estimate the probability of purchasing a specific garment and to derive the inverse Mill's ratios included in the conditional AIDS model. The parameters pertaining to the unconditional expenditure share equation are recovered following McDonald and Moffit (1980) decomposition. While there may be some efficiency loss in comparison to a multivariate probit model or through a procedure that combines the two steps, this approach produces consistent parameter estimates for the probit and the conditional AIDS models (Shonkwiler and Yen, 1999). The budget share is specified as follows:

$$
w_{i t}=\max \left(0, \bar{w}_{i l}\right) \text {. }
$$

To illustrate the full model, let $y_{i l}$ be a binary variable that is equal to 1 if the individual household makes a purchase of the $i$ th garment at time $t$ and 0 otherwise. The basic structure of the binary choice model is as specified as

$$
\begin{aligned}
& P\left(y_{i t}=1\right)=P\left(\bar{w}_{i t}>0\right)=\Phi\left(\mathbf{X}_{i t} \boldsymbol{\theta}_{i}\right) \\
& \mathbf{X}_{i t} \boldsymbol{\theta}_{i}=c_{i}+\sum \eta_{i} d_{t}+\sum s_{\mathrm{ij}} \ln p_{j t}+\nu_{i} \ln \left(m_{t}\right) .
\end{aligned}
$$

The inverse Mill's ratio $\lambda_{i t}$ for the household that consumes the $i$ th garment is

$$
\lambda_{i t}=\phi\left(\mathbf{X}_{i t} \boldsymbol{\theta}_{i}\right) / \Phi\left(\mathbf{X}_{i t} \boldsymbol{\theta}_{i}\right),
$$

where $\varphi\left(\mathrm{X}_{i t} \boldsymbol{\theta}_{i}\right)$ and $\Phi\left(\mathrm{X}_{i i} \boldsymbol{\theta}_{i}\right)$ represent the normal probability density and the cumulative density functions of the probit model, respectively. The second step of the estimation process consists of estimating a censored dynamic expenditure share model. The model is specified as

$$
\begin{aligned}
& \bar{w}_{i t}=\mathrm{X}_{i t} \boldsymbol{\Gamma}_{i}+\sigma_{i} \lambda_{i t}+\varepsilon_{i t}, \\
& \mathrm{X}_{i t} \boldsymbol{\Gamma}_{i}=\alpha_{i}+\sum z_{i} d_{i t}+\sum \gamma_{i j} \ln \left(p_{j t}\right)+\beta_{i}\left(d_{t}\right) \ln \left[m t / \pi\left(p_{l}, d_{l}\right)\right]+\varepsilon_{i t},
\end{aligned}
$$

with the following restrictions: adding-up, (i.e.

$$
\begin{gathered}
\sum_{i}^{N} \alpha_{i}=1, \sum_{i}^{N} \beta_{i}=0, \sum_{i}^{N} z_{i}=0, \text { and } \sum_{i}^{N} \sigma_{i}=0 \text { ) homogeneity } \\
\left(\sum_{i}^{N} \gamma_{i j}=0\right), \text { and symmetry (i.e., } \gamma_{i j}=\gamma_{j i} \text { ). }
\end{gathered}
$$

It is important to note that this study recognizes the controversy surrounding the concept of adding-up when dealing with censored dataset. Per Pudney (1989) recommendation and consistent with Yen and Huang (2003) application, this study estimates $N-1$ equations and treats the remaining equation as a residual demand. 
The estimation procedure seeks to find the estimated values of the parameter vectors $\Gamma_{i}$ and $\sigma_{i}$ using a seemingly unrelated regression. The inclusion of detailed demographic variables and interactions between demographic and expenditure variables in the model is enough to account for most of the heterogeneity in the error variances error term is likely to be heteroskedastic alleviating heteroskedasticity problems that may occur as a result of the error term structure (Blundell et al., 1993).

The marginal impacts of socioeconomic and demographic variables, seasons, past expenditure shares, prices, and expenditures on the decision and conditional share equations are directly tested from the estimated model using significance test based on the $t$-statistics. Further, the unconditional marginal effects, price elasticities, and expenditure elasticities are derived and their impacts are assessed based on the magnitude of their estimated values. Price (expenditure) elasticity of probability of purchase measures the percentage change in probability of purchasing a garment following a percentage change in price (total expenditures in apparel) for the consuming household. The conditional price (expenditure) elasticity of demand is the percentage change in apparel consumption for the consuming household following a percentage change in apparel price (total apparel expenditure).

From equation (6), the marginal probability of the vector of explanatory variables is derived as

$$
\partial \Phi\left(\mathrm{X}_{i t} \boldsymbol{\theta}_{i}\right) / \partial d_{t}=\eta_{i} \phi\left(\mathbf{X}_{i t} \boldsymbol{\theta}_{i}\right) .
$$

The expenditure and price probability elasticity are defined as

$$
\begin{aligned}
& e_{i x}^{y}=\nu_{i} \lambda_{i t} \\
& e_{i p}^{y}=s_{i j} \lambda_{i t} .
\end{aligned}
$$

The conditional expenditure elasticity $e_{i . \mathrm{x}}^{c}$ is defined using equation (8). Applying the same principles as above, the conditional expenditure elasticity is specified as

$$
e_{i \mathrm{ix}}^{c}=1+\left[\beta_{i}\left(d_{t}\right)-\nu_{i} \sigma_{i} \Lambda_{i}\right] / w_{i},
$$

where the parameter $\beta_{i}\left(d_{t}\right)$ is the estimated value of the coefficient on expenditure variable in the conditional mean equation, and $\Lambda_{i}$ is equal to $\lambda_{i t^{2}}-\lambda_{i t} \Phi\left(-\mathrm{X}_{i t} \boldsymbol{\theta}_{i}\right)$, while $\nu_{i}, \sigma_{i}$, and $w_{i}$ remain as defined earlier. The conditional price elasticity is based on Eales and Unnevehr (1988) and is defined as

$$
e_{i p}^{c}=k_{i j}+\left(\gamma_{i j}-s_{i j} \sigma_{i} \Lambda_{i}\right) / w_{i},
$$

where $k_{i j}=-1$ for $i=j$ and zero elsewhere and $\varsigma_{i j}>$ is the vector of price parameters in the conditional mean equation.

From the expressions of the price and expenditure elasticities, the unconditional elasticities are defined as

$$
\begin{aligned}
& e_{i x}^{u}=e_{i x}^{p}+e_{i x}^{c} \\
& e_{i p}^{t \prime}=e_{i p}^{p}+e_{i p}^{c} .
\end{aligned}
$$

The determination of the elasticity parameters helped evaluate the relationships between different types of apparel across seasons, demographics, and regions. 


\section{JFMM 9,4}

\section{2}

Table I.

Description of the variables used in the analysis
The effects of higher cotton blends and demographic variables on expenditure share for different garments are evaluated through their marginal impacts measured by the magnitude of their respective parameter estimates. The estimated expenditure share models for each category of apparel are further evaluated to identify regions and various demographic groups with demand growth potential for apparel.

\section{The data}

The dataset used in this study is based on surveys conducted by the American shoppers panel, which collects data on end-use products such as apparel and socioeconomic and demographic profiles of the participating households. The original dataset covered 16,000 households surveyed monthly from 1990 to 1999. For the purpose of this study, male shirts (MSHIRT), male jeans (MJEAN), male shorts (MSHORT), male slacks (MSLACK), female slacks (FSLACK), female jeans (FJEAN), female shorts (FSHORT), skirts (SKIRT), and dresses (DRESS) were retained. Data transformations were conducted to generate the expenditure share variables, price variables, aggregate-level demand, and total expenditures on a quarterly basis. A detailed description of the variables used in this study is shown in Table I. The sparse

\begin{tabular}{|c|c|}
\hline Variable & Variable definition \\
\hline Age & $\begin{array}{l}\text { Continuous variable indicating the age of the buyer from which four age } \\
\text { categories were derived (DAGE1 = } 1 \text { if AGE under } 21 \text {, and } 0 \text { elsewhere, } \\
\text { DAGE } 2=1 \text { if AGE between } 21 \text { and } 30 \text {, and } 0 \text { elsewhere, DAGE3 = } 1 \text { if } \\
\text { AGE between } 31 \text { and } 55 \text {, and } 0 \text { elsewhere, and DAGE } 4=1 \text { if AGE over } \\
55 \text {, and } 0 \text { elsewhere) }\end{array}$ \\
\hline Gender & Dummy variable for buyer's gender $(1=$ female, and $0=$ male $)$ \\
\hline INCOM & $\begin{array}{l}\text { Categorical variable that indicates the different income strata within the } \\
\text { sample (INCOM1 = I if INCOM under } \$ 10,000 \text { and } 0 \text { elsewhere, INCOM } \\
2=1 \text { if INCOM between } \$ 10,000 \text { and } \$ 20,000 \text { and } 0 \text { elsewhere, } \\
\text { INCOM } 3=1 \text { if INCOM between }=\$ 20,000 \text { to } \$ 30,000 \text { and } 0 \text { elsewhere, } \\
\text { INCOM } 4=1 \text { if INCOM between } \$ 30,000 \text { to } \$ 45,000 \text { and } 0 \text { elsewhere, } \\
\text { INCOM5 }=1 \text { if INCOM between } \$ 45,000 \text { to } \$ 60,000 \text {, and } 0 \text { elsewhere, and } \\
\text { INCOM6 }=1 \text { if INCOM = over } \$ 60,000 \text { ) }\end{array}$ \\
\hline HHSZ & Continuous variable indicating household's size \\
\hline Child & $\begin{array}{l}\text { Dummy variable indicating presence or absence of children }(0=\text { no } \\
\text { children and } 1 \text { if presence of children) }\end{array}$ \\
\hline Race & $\begin{array}{l}\text { Categorical variable used to create dummy variables for each of the four } \\
\text { racial groups (WIITES, AFAMER, ASIANS, and OTHERS) }\end{array}$ \\
\hline FEMEMP & $\begin{array}{l}\text { Dummy indicating female employment status }(0=\text { female not employed } \\
\text { and } 1=\text { employed) }\end{array}$ \\
\hline Region & $\begin{array}{l}\text { Categorical variable that indicates the region of residence of the } \\
\text { respondent and used to derive four regional dummies (NEAST, SOUTH, } \\
\text { MDWEST, and } 4=\text { WEST) }\end{array}$ \\
\hline IMPTED & $\begin{array}{l}\text { Dummy variable indicating product origins }(1=\text { imported and } \\
0=\text { domestic })\end{array}$ \\
\hline Blend & $\begin{array}{l}\text { Categorical variable that indicates the different level of cotton blend in the } \\
\text { purchased item and used to derive dummy variable for different blends } \\
\text { such as ( } 50 \text { COTN if cotton blend is less than } 50 \text { percent, } 62 C O T N \text { if blend } \\
\text { between } 50 \text { and } 74 \text { percent, } 87 \text { COTN = if cotton blend between } 75 \text { and } 99 \\
\text { percent, 100COTN if item is made of } 100 \text { percent cotton blend) }\end{array}$ \\
\hline
\end{tabular}


nature of the original data set due primarily to infrequent purchases because of the semi-durable nature of apparel led to aggregate the data to quarterly frequency. The resulting dataset contained 1,880 households with a total of 29,964 observations.

\section{Empirical results}

This study seeks to determine the price and expenditure elasticities for apparel products, which among others, necessitates a probit and SUR estimations. A total of 306 parameters were estimated for the probit model, while for the censored SUR model, eight equations were estimated with a total of 348 parameters. The equation for DRESS was dropped and its corresponding parameters recovered using the principle of adding-up as earlier described. The estimation results of the probit model and censored SUR are not presented but can be obtained from the authors. Tables II-IV show the results on the probability elasticities, unconditional price and expenditure elasticities, and unconditional marginal demographic and product characteristics impacts.

The unconditional elasticities, also referred to as total elasticities, are the sum of probability elasticities and conditional elasticities. The decomposition captures the effects of changing prices and expenditures on the probability and level of consumption (Yen and Huang, 2002). Thus, the results of the elasticities comprise the probability elasticity matrix (Table II) and the unconditional Marshallian elasticity matrix (Table III). Heterogeneity between households in terms of elasticities was captured through the marginal expenditure value, which reflects the effects of socioeconomic and demographic characteristics.

\section{Oun-price and expenditure elasticities}

Table II provides price and expenditure elasticities of probability of purchasing apparel products, which capture the effects of changing prices and expenditures on the probability of consumption. The own-price elasticity of probability of purchasing all apparel products, except male shirts, were negative and greater than one in absolute value, implying that 1 per cent increase in price of the product would decrease the probability of purchasing the same items by more than 1 per cent. The results also show that all probabilities of purchase, except for male shirts, are expenditure inelastic, implying that a 1 per cent increase in total expenditure results in an increase of the probability of purchasing the products by less that 1 per cent. The noted difference for male shirts compared to the other products may be explained by the fact that this category contains high priced shirts (dressed shirts) and low-price shirts (ordinary shirts) as well.

\begin{tabular}{|c|c|c|c|c|c|c|c|c|c|c|}
\hline Variables & MSIIIRT & FJEAN & MJEAN & MSHORT & MSLACK & FSLACK & SIIIRT & FSHORT & DRESS & \\
\hline PMSHIRT & 0.648 & 0.064 & -0.009 & 0.155 & -0.039 & -0.026 & -0.067 & 0.141 & -0.011 & \\
\hline PFJEAN & -0.018 & -1.293 & -0.089 & 0.108 & 0.103 & 0.127 & -0.122 & 0.063 & -0.050 & \\
\hline PMJEAN & -0.192 & -0.169 & -1.420 & 0.072 & -0.272 & -0.072 & 0.130 & 0.047 & -0.052 & \\
\hline PMSHORT & 0.039 & 0.097 & 0.063 & -2.005 & 0.094 & -0.089 & -0.084 & -0.143 & -0.007 & \\
\hline PMSLACK & -0.275 & -0.319 & -0.434 & -0.294 & -2.829 & 0.093 & -0.396 & -0.110 & -0.023 & \\
\hline PFSLACK & 0.095 & -0.178 & -0.063 & -0.162 & -0.888 & -2.447 & -0.434 & -0.570 & -0.007 & \\
\hline PSITRT & 0.007 & -0.308 & 0.002 & 0.163 & 0.116 & 0.046 & -2.941 & 0.257 & 0.114 & Table II. \\
\hline PFSHORT & 0.125 & 0.020 & 0.064 & 0.165 & 0.068 & -0.192 & -0.086 & -1.928 & -0.096 & Price and expenditure \\
\hline PDRESS & 0.028 & -0.413 & -0.236 & -0.148 & 0.285 & -0.074 & 0.489 & -0.325 & -2.522 & elasticities of probability \\
\hline TEXPEND & -0.262 & 0.608 & 0.872 & 0.577 & 0.852 & 0.524 & 0.561 & 0.507 & 0.657 & of purchasing apparel \\
\hline
\end{tabular}

US consumer purchasing decisions

373

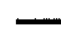




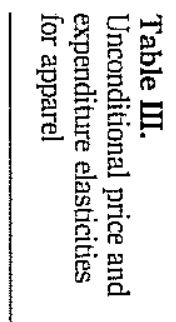

\begin{tabular}{|c|c|c|c|c|c|c|c|c|c|}
\hline Variables & MSHIRT & FJEAN & MJEAN & MSHORT & MSLACK & FSLACK & SKIRT & FSHORT & DRESS \\
\hline PMSHIRT & -0.327 & 0.007 & -0.032 & -0.025 & 0.037 & -0.020 & -0.034 & -0.056 & 0.047 \\
\hline PFJEAN & -0.051 & -1.640 & -0.217 & 0.035 & $-0,004$ & 0.053 & -0.188 & 0.011 & -0.042 \\
\hline PMJEAN & -0.178 & -0.262 & -1.704 & 0.039 & -0.280 & -0.182 & 0.078 & -0.013 & -0.060 \\
\hline PMSHORT & -0.123 & 0.011 & 0.031 & -2.170 & -0.010 & -0.168 & -0.185 & -0.174 & -0.102 \\
\hline PMSLACK & -0.174 & -0.434 & -0.498 & -0.382 & -2.674 & -0.081 & -0.725 & -0.269 & -0.062 \\
\hline PFSLACK & 0.086 & -0.254 & -0.258 & $-0,249$ & -1.002 & -2.340 & -0.585 & -0.567 & -0.160 \\
\hline PSKIRT & 0.025 & -0.392 & -0.046 & 0.013 & -0.288 & -0.151 & -2.256 & 0.009 & -0.134 \\
\hline PFSHORT & -0.069 & -0.039 & -0.013 & 0.110 & -0.087 & -0.208 & -0.255 & -2.030 & -0.110 \\
\hline PDRESS & 0.015 & -0.379 & -0.213 & -0.120 & 0.267 & -0.047 & 0.479 & -0.294 & -3.383 \\
\hline TEXPEND & 0.415 & 0.987 & 1.195 & 0.840 & 1.073 & 0.702 & 0.518 & 0.738 & 0.734 \\
\hline
\end{tabular}




\begin{tabular}{|c|c|c|c|c|c|c|c|c|c|c|}
\hline Variables & MSHIRT & FJEAN & MJEAN & MSHORT & MSLACK & FSLACK & SKIRT & FSHORT & DRESS & Dirchasing \\
\hline DAGE1 & -0.062 & 0.183 & -0.110 & -0.109 & 0.031 & 0.179 & 0.769 & 0.394 & 0.005 & decisions \\
\hline DAGE2 & -0.034 & 0.010 & -0.038 & -0.069 & 0.548 & 0.170 & 0.604 & 0.121 & 0.257 & \\
\hline DAGE4 & -0.012 & $-0,082$ & 0.073 & 0.188 & 0.185 & 0.072 & 0.400 & 0.006 & 0.116 & \\
\hline FEMEMP & -0.015 & 0.010 & 0.005 & 0.032 & -0.068 & 0.068 & 0.453 & 0.074 & $-0,094$ & \\
\hline CHILD & 0.017 & $-0.2 \mathrm{i}]$ & 0.010 & 0.121 & -0.361 & -0.620 & -0.011 & -0.083 & 0.350 & 375 \\
\hline MPTED & 0.020 & 0.043 & 0.193 & -0.104 & -0.091 & 0.008 & 0.589 & -0.131 & -0.153 & \\
\hline GENDER & 0.075 & 0.412 & -0.317 & -0.432 & -0.858 & 0.899 & 1.519 & 0.801 & -0.230 & \\
\hline NEAST & 0.010 & -0.010 & 0.010 & -0.106 & -0.310 & 0.001 & 0.831 & -0.192 & -0.253 & \\
\hline MDWEST & -0.008 & -0.022 & 0.000 & -0.056 & 0.041 & 0.092 & 0.730 & -0.076 & -0.112 & \\
\hline SOUTH & 0.003 & -0.071 & -0.035 & 0.069 & -0.214 & 0.071 & 1.069 & 0.033 & 0.046 & \\
\hline $\mathrm{INCl}$ & 0.295 & -0.168 & -0.138 & -0.176 & 0.007 & 0.034 & -0.536 & -0.270 & -1.234 & \\
\hline $\mathrm{INC2}$ & 0.321 & -0.020 & 0.018 & -0.265 & -0.049 & -0.381 & -0.467 & -0.232 & -1.347 & \\
\hline INC3 & 0.121 & -0.027 & 0.092 & -0.148 & -0.273 & -0.385 & -0.478 & -0.111 & -0.213 & \\
\hline $\mathrm{INC4}$ & 0.118 & 0.011 & 0.018 & -0.115 & -0.073 & -0.473 & -0.144 & -0.063 & -0.300 & \\
\hline INC5 & 0.021 & -0.020 & 0.050 & 0.009 & 0.303 & -0.021 & -0.090 & -0.059 & 0.078 & \\
\hline AFAMER & 0.098 & -0.005 & -0.107 & -0.206 & -0.401 & 0.080 & 0.699 & -0.219 & 1.365 & \\
\hline ASIANS & -0.066 & 0.101 & 0.007 & 0.146 & 1.032 & 1.169 & 0.687 & -0.161 & 0.066 & \\
\hline OTRACE & -0.309 & -0.079 & 0.156 & 0.014 & 0.609 & -0.080 & -0.131 & -0.288 & 1.309 & \\
\hline CTN100 & 0.202 & 0.356 & 0.353 & 0.523 & -0.559 & 0.172 & 0.355 & 0.582 & 0.775 & \\
\hline CTN62 & -0.075 & -0.041 & -0.054 & -0.170 & -0.301 & 0.115 & -0.175 & -0.089 & 0.025 & \\
\hline CTN87 & 0.019 & 0.285 & 0.139 & 0.272 & 0.009 & 0.921 & 0.061 & 0.415 & 0.505 & Table IV. \\
\hline FQRTER & -0.020 & -0.028 & 0.005 & -0.032 & -0.083 & -0.049 & -0.057 & -0.014 & -0.045 & Unconditional marginal \\
\hline SQRTER & 0.008 & -0.265 & -0.290 & 1.226 & -0.095 & 0.357 & -0.141 & 1.251 & 0.154 & demographic and product \\
\hline TQRTER & 0.035 & -0.220 & -0.141 & 1.146 & -0.145 & 0.221 & 0.123 & 1.057 & 0.147 & characteristic impacts \\
\hline
\end{tabular}

Results in Table III summarize the overall responsiveness of expenditure share in each category of apparel to price and total expenditure changes. It can be inferred that the demand for male shirts, male shorts, female jeans, female slacks, skirts, female shorts, and dresses are expenditure inelastic, while the unconditional demand for male jeans and male slacks are expenditure elastic. With regard to responsiveness to changes in own-price, it was observed that all apparel products with the exception of male shirts are own-price elastic. The unconditional cross-price elasticities were generally negative and less than unity implying that increase in price of one garment would lead to a relatively lower decrease in demand of garment of other type.

The elasticity estimates obtained in this study, generally, are within the limits of those found in the literature. Expenditure elasticities found in previous studies ranged between 0.4 and 2.5, while those of own-price elasticities were between -1.0 and -2.0 , suggesting that apparel expenditures are price-elastic. These findings are consistent with the results obtained by Jones and Hayes (2002) in the United Kingdom. Thus, while recent studies have determined that the luxury aspect of apparel product is no longer supported, this study suggests that the classification of apparel as a luxury, necessary, or price sensitive good depends on garment type.

\section{Demographic and product characteristic variables}

The results of the unconditional marginal effects of demographic and product characteristics on apparel demand are summarized in Table IV. The analysis focused 
JFMM 9,4 on the total effects of age, income, race, gender, products origins, cotton blend, and region. The relatively high magnitude of the effects of these variables was indicative of their potential impacts on apparel demand growth.

The effects of age on apparel demand are difficult to ascertain because this study uses the age of the primary buyer, which may not be the primary wearer. However, there is indication that expenditure for female jeans is higher for consumers under the age of 31, while expenditure for male shorts, male shirts, and male jeans appear higher for consumers over the age of 31 . Further, it was observed that buyers in the age group $31-55$ spent less for skirts, female slacks, female shorts, and dresses than buyers of any other age groups. The impact of female employment status was most noticeable with skirts, female slacks, and female shorts. Households with employed females had higher expenditure shares for skirts, female slacks, and female shorts. For households with at least one child, expenditure shares of female jeans, female slacks, and dresses were lower, and the expenditure shares of skirts and female shorts were higher than households with no child. The effects of gender are significant and illustrate differences in shopping patterns between male and female buyers. While the expenditure shares of female jeans, female slacks, skirts, and female shorts were higher for female buyers compared to male buyers, the expenditure shares of male jeans, male shorts, male slacks, and dresses were lower.

Regarding income levels, there were minimal differences in purchasing habits of apparel items across income categories. However, households with higher income levels spend more on female jeans, male shorts, male slacks, female slacks, and skirts. Expenditure shares of male shirts and male jeans appear to decrease with higher income levels.

The marginal expenditure share of male shirts for African-American households was 9 per cent higher, while expenditure shares of male jeans, male shorts, male slacks, and female slacks, and skirts were all lower. The expenditure shares for Asian-American households of male shorts, male slacks, female slacks, skirts, and dresses were higher than their White-American counterparts. Expenditure shares of male shirts, female jeans, female slacks, skirts, and dresses for households of other races were lower than White-American households.

The evaluation of the unconditional effects of product characteristics revealed that with the exception of male jeans, skirts, and female jeans, product origin was not a determining factor in household apparel expenditure. The results indicated that expenditure shares of male jeans and skirts were generally higher for imported products compared to domestically produced products. Furthermore, the results showed that compared to items with less than 50 per cent of cotton blend, expenditure share of male shirts, female jeans, male jeans, male shorts, skirts, dresses, and shorts were higher if products contained 100 per cent of cotton, while expenditure share of male slacks was lower.

The analysis of the effects of seasons on consumer expenditures indicates no significant differences in consumer expenditure patterns between the first and the last quarters of the year. However, consumers appeared to spend less on female jeans, male jeans, and female shorts, and more on male shorts in the second and third quarters compared to the last quarter. Similarly with the exception of male shirts, there were no significant regional differences in apparel expenditures between the West and the remaining regions of the United States. 


\section{Summary and conclusions}

The unconditional price and expenditure elasticities and the unconditional marginal effects of the demographic and the product characteristics variables have direct marketing implications, as they enable marketing managers to make more informed marketing decisions, especially in the design of effective marketing mixes. Elasticity estimates and marginal demographic impacts are effective tools to gauge the effectiveness of short-term marketing strategies such as price promotion applied across various population strata.

The effectiveness of any marketing strategies is dependent upon market characteristics such as own- and cross-price elasticities. Price promotion may have the desired effects for apparel that are own-price elastic (i.e. male jeans, male shorts, male slacks, female slacks, female shorts, female jeans, skirts, and dresses) as their market shares are expected to rise under a price promotion strategy. However, mark-up pricing has to be designed carefully to avoid losing market shares that may not be recovered. Mark-up pricing strategy would be effective for products such as male shirts. Since male shirts are price-inelastic, the gain from increased price for these items would more than offset possible market share losses provided that the prices of their imported counterparts remained unchanged. Inelastic cross-price elasticities for the majority of the garments in this study indicate that the effects of pricing policies would be limited to the targeted products. Thus, price promotion or price increase for, say, male shirts would affect market share for male jeans at a lesser proportion.

Gupta (1988) stated that price promotion affects consumer behaviour at the category and the brand levels. Thus, consumers may switch to a more expensive brand within the same category of apparel or they may stockpile the same garment types by accelerating their purchase frequency. In this study, information about brand names were not available, thus the effects of price on brand were not quantified. However, it is reasonable to believe that more stockpiling may take place, simply because of the durable nature of apparel. The derived elasticities only addressed the inter-garments effects with the understanding that price promotions also have inter-brands effects.

Results on unconditional marginal socioeconomic and demographic effects indicated that marketing strategies that promote male jeans, male shorts, male slacks, female slacks, and dresses to consumers over the age of 55 might be effective. Similarly, consumers under the age of 31 might be responsive to promotion of male slacks, female slacks, skirts, female shorts, and dresses. There is no indication that expenditure share of male garments increase with female buyers. African-American households appeared to purchase less male jeans, male shorts, male slacks, and female shorts than White-American households. This may indicate differences in tastes, effects of other variables such as income, or sensitivity to prices. Similarly, American households of other races purchased less male shirts, female jeans, female slacks, skirts, female shorts, and dresses. Under these circumstances, marketing campaigns targeting these demographic groups could be a viable strategy to increase consumption of the indicated items. This strategy also may be useful to boost consumption of male shirts and female jeans by consumers over the age of 55 .

This study shows that consumer expenditures, generally, are not influenced by product origins. Thus, marketing strategies solely focused on product origins may not result in increased market share of domestically produced apparel. The effects of different blends, however, suggested that market share of male and female slacks may 


\section{JFMM 9,4}

be increased if cotton blends in these items were reduced. Moreover, market shares of male shirts, female jeans, male jeans, male shorts, and dresses were higher for items containing 100 per cent of cotton blend compared to similar products with lower cotton blend.

This study is one of the few that have attempted to model consumer demand for apparel using disaggregated apparel products, detailed demographic factors, and apparel characteristics such as fibre contents and product origins. Most of the previous studies in this area have been based on the data from consumer expenditure survey and have analyzed clothing as an aggregated product, which limit their marketing implications. However, the interpretation of the findings of this study should be done with caution because it is based on a survey that is overwhelmingly comprised of White-American households (94 per cent). Furthermore, the survey data did not include information related to brands, and thus, how consumers react to price change is not fully known.

\section{References}

Abel-Ghany, M. and Schwenk, F.N. (1993), "Functional forms of household expenditure patterns in the United States", Home Economics, Vol. 17, pp. 325-41.

Blundell, R., Pashardes, P. and Weber, G. (1993), "What do we learn about consumer demand pattems from micro data", American Economic Review, Vol. 83, pp. 570-97.

Brown, B.W. and Walker, M.B. (1989), "The random utility hypothesis and inferences in demand systems", Econometrica, Vol. 57, pp. 815-29.

DeWeese, G. and Norton, M.J. (1991), "Impact of married women's employment on individual households expenditures for clothing", Joumal of Consumer Affairs, Vol. 25, pp. 235-7.

Eales, J. and Unnevehr, L. (1988), "Beef and chicken product demand", American Journal of Agricullural Economics, Vol. 70, pp. 521-30.

Gupta, S. (1988), "Impact of sales promotions on when, what, and how much to buy", Joumal of Marketing, Vol. 25, pp. 342-55.

Jones, R. and Hayes, S. (2002), "The economic determinants of clothing consumption in the UK 1987-2000", Journal of Fashion Marketing and Managemenl, Vol. 6, pp. 326-39.

Lee, J., Sherman, D. and Wang, H. (1997), "Apparel expenditures patterns of elderly consumers: a life-cycle consumption model", Family and Consumer Science Research Journal, Vol. 26, pp. $109-47$.

McDonald, J.F. and Moffit, R.A. (1980), "The uses of Tobit analysis", The Review of Economics and Slatistics, Vol. 62, pp. 318-21.

Mokhtari, M. (1992), "An alternative model for US clothing expenditures: application of cointegration techniques", Joumal of Consumer Affairs, Vol. 26, pp. 305-23.

Norum, P.S. (1989), "Economic analysis of quarterly household expenditure on apparel", Home Economics Research Journal, Vol. 17, pp. 228-40.

Nonum, P.S. (1999), "The demand for accessories, footwear, and hosiery: an economic analysis", Joumal of Fashion Marketing and Management, Vol. 3, pp. 56-64.

Perali, F. and Chavas, J. (2000), "Estimation of censored demand equations from large cross-section data", American Joumal of Agricultural Economics, Vol. 82, pp. 1022-37.

Pudney, S. (1989), Modelling Individual Choice: The Economic of Comers, Kinks, and Holes, Blakwell, Oxford and New York, NY. 
Schwer, K. and Daneshvary, R. (1995), "Symbolic attributes and emulatory consumption: the case of rodeo fan attendance and the wearing of western clothing", Joumal of Applied Business Research, Vol. 11, pp. 7480.

Shonkwiler, J.S. and Yen, S. (1999), "Two-step estimation of a censored system of equations", American Joumal of Agricultural Economics, Vol. 81, pp. 972-82.

US Department of Agriculture-Economic Research Service (2004), Cotton and Wool Siluation and Outlook Yearbook, US Department of Agriculture-Economic Research Service, Washington, DC: CWS-2004, November.

US consumer purchasing decisions

U.S. Department of Commerce-Census Bureau (2004), Statistical Abstract of the United States, Washington, DC, U.S. Department of Commerce-Census Bureau.

Wagner, J. (1986), "Expenditures for household textiles and textile home furnishings: an Engle curve analysis", Home Economics Research Joumal, Vol. 15, pp. 21-31.

Yen, S. and Huang, C.L. (2002), "Cross-sectional estimation of US demand for beef products: a censored system demand", Journal of Agricultural and Resource Economics, Vol. 27, pp. 320-34.

\section{Further reading}

Blundell, R. (1998), "Consumer demand and intertemporal allocations: Engel, Slutsky, and Frisch", in Strom, S. (Ed.), Econometrics and Economic Theory in the 20th Century, Econometric Society Monographs, Cambridge University Press, Cambridge, England, pp. 147-66. 
